Madrygal. Revista de Estudios Gallegos

ISSN: 1138-9664

\title{
Crónica das luces e sombras de Madrid
}

\author{
Lidia Teixeiro $^{1}$
}

O curso 2015-2016 será recordado pola intensidade dos acontecementos acaecidos no seo da comunidade galega en Madrid. Entre as moitas cousas que cumprirá destacar, sen dúbida, o 2016 pasará por ser o ano en que Sabino Torres faleceu, aos noventa e dous anos, apenas publicado o primeiro número do seu derradeiro proxecto editorial, Olga (en parcería con Vicente Araguas, Manuel Pereira e Rafa Yañez), e, ao mesmo tempo, tamén por ser o ano en que se verá recoñecida a traxectoria nos estudos galicianistas da profesora Carmen Mejía Ruiz, co galardón do Pedrón de Honra, outorgado pola Fundación Pedrón de Ouro. Novos proxectos, despedidas, un período de fortes contrastes que trouxo, á par de novas iniciativas culturais e académicas, momentos de fonda tristura.

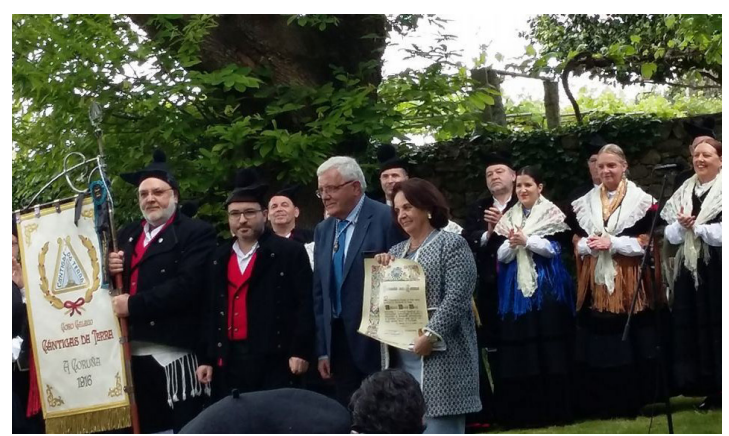

Entrega do premio Pedrón de Honra a Carmen Mejía Ruiz
Comezando polos aspectos máis vinculados á docencia do galego na universidade, a demanda de continuidade coas actividades formativas universitarias en lingua galega levou a crear un grupo de aprendizaxe informal, semanal. Lingua de Luns, o nome co que foi bautizado, parello ao estudo da lingua, participou activamente doutras actividades organizadas ou asistidas polo CEG da UCM, en Madrid e mais no estranxeiro. Dentro das reunións, traballaron especialmente aspectos propios da investigación científica; aprenderon a elaborar abstracts, a estruturar un artigo científico, a traballar coa bibliografía, etc. Co gallo de afondar no coñecemento sobre a colección Benito Soto, o alumnado realizou unha entrevista a Sabino Torres no despacho presidencial do Ateneo de Madrid, espazo que foi facilitado por Miguel Losada (responsable da Cátedra de estudos galegos desta institución). Sobre as gravacións realizadas elaborouse un pequeno documental sobre a vida deste editor e escritor, aínda inédito, coa finalidade de ser proxectado e empregado para futuros estudos da literatura galega de posguerra. Ademais, con posterioridade, Lingua de Luns viu recoñecido o seu labor coa aceptación e presentación de varias comunicacións froito destes traballos no Congreso Internacional de Identidade e Xénero en Galicia, celebrado en Varsovia durante os días 9, 10 e 11 de maio.

\footnotetext{
Universidad Complutense de Madrid, Departamento de Filología Románica, Filología Eslava y Lingüística General; Centro de Estudos Galegos.

E-mail: lilope03@ucm.es
} 
Ademais de expoñer os resultados das súas pesquisas e asistir ás mesas redondas e palestras, o estudantado tamén tivo ocasión de participar nunha intercambio lingüístico, experiencia mantida co alumnado do Centro de Estudos de Varsovia. Recibidos pola lectora Rebeca Lema nas súas aulas, ambos os dous grupos de estudantes realizaron actividades destinadas a fomentar o coñecemento mutuo das dúas culturas en diálogo e a mellorar as súas competencias lingüísticas. Dúas semanas despois, en Madrid, e grazas ao programa de mobilidade de docentes Erasmus+, a profesora Rebeca Lema foi recibida no CEG da Universidad Complutense de Madrid onde puido achegarse até ás súas clases, asistir a unha das celebracións do Día das Letras Galegas da cidade (a levaba a cabo polo sección de galego na Escola Oficial de Idiomas Xesús Maestro) e impartir un seminario sobre a tradución e a interpretación en Galicia, unha das súas áreas de especialización.

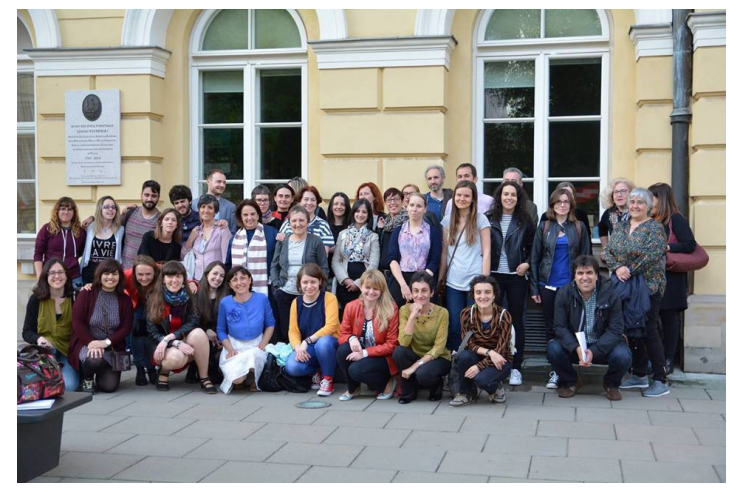

Asistentes ao Congreso Internacional Identidade e Xénero en Galicia, na Universidade de Varsovia

A estadía da lectora de Varsovia non foi a única acollida realizada polo CEG durante este curso. A finais de xaneiro, a doutoranda Ann Lammers, da Universidade de Kiel, xa permanecera quince días na nosa universidade durante os cales, alén de colaborar activamente nas actividades cotiás do centro e coñecer o seu funcionamento, impartiu un seminario sobre a materia da que é especialista, a narrativa de Manolo Rivas e a transmisión da memoria da guerra civil e a represión.

Seguindo con outros aspectos académicos, debemos mencionar tamén a concesión do selo de calidade FECYT a Madrygal. Revista de Estudios Gallegos e a organización das xornadas en homenaxe a Don Alonso Zamora
Vicente, introdutor do estudo da lingua galega na Universidad Complutense de Madrid.

A distinción da FECYT, outorgada pola Fundación Española para la Ciencia y la Tecnología, supón un recoñecemento ao rigor científico co que a revista se elabora, seguindo sempre pautas formais e de contido que redundan nunha estandarización do seu formato e facilitan a súa posterior consulta e indexación en novas bases de datos. A avaliación á que foi sometida por parte da entidade independente para ser merecente do selo garante que a publicación establece protocolos de comunicación cos seus autores e autoras, mantendo o anonimato nas revisións a cegas por pares e delimitando cotas de participación internacionais, nacionais e para persoas da mesma universidade.

As xornadas "Alonso Zamora Vicente. 100 años de su nacimiento" enmarcáronse na VI Semana Complutense de las Letras, contando co apoio do Centro de Estudos Galegos da UCM tanto na organización das xornadas coma no deseño e desenvolvemento dunha serie de propostas asociadas. Durante cinco días, e coa adhesión de numerosas institucións, realizáronse actividades en lembranza do que fora Catedrático de Filoloxía Románica, conmemorando toda unha vida de dedicación á súa paixón, as linguas. O 18 de abril, inaugurábase o evento cunha xornada de mesas redondas onde se deu conta das principais facetas do profesor como académico da lingua castelá, dialectólogo, escritor e mestre. Para falar da súa relación coa lingua galega e da súa etapa compostelá acompañounos o profesor Francisco Fernández Rei, da Universidade de Santiago de Compostela. Así mesmo, no marco da celebración, inaugurouse unha exposición bibliográfica cos fondos máis relevantes de don Alonso. Ao día seguinte, tivo lugar un obradoiro de tradución

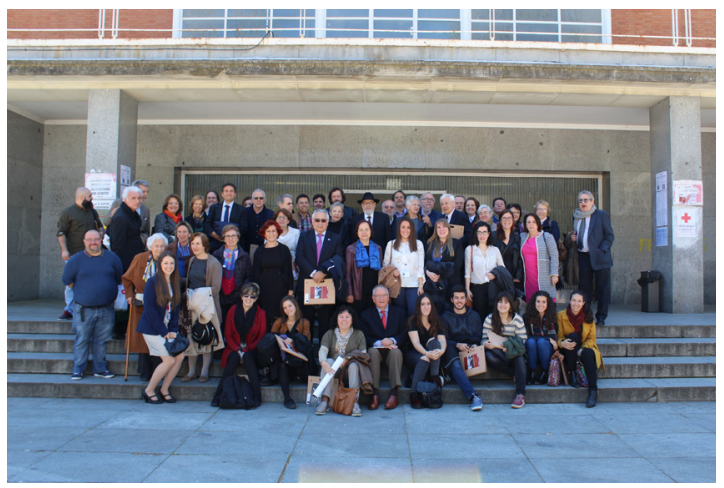

Asistentes ás xornadas “Alonso Zamora Vicente. 100 años de su nacimiento" 
multilingüe. Tras unha introdución á obra literaria de Zamora Vicente, a cargo de Sebastian Stratan, o alumnado participante, en compañía das e dos docentes da titulación de románicas, traduciu a diferentes linguas románicas (portugués, galego, romanés, catalán) o relato "Tarde en Rosales", do libro Primeras Hojas. Seguidamente, despois de comentar as dificultades de tradución para cada idioma, procedeuse a unha lectura multilingüe do mesmo. O derradeiro día, 22 de abril, tivo lugar unha actividade conxunta da área de galego-portugués, onde, ademais de dar por finalizadas as xornadas, se realizaba a despedida académica do profesor Denis Canellas de Castro Duarte, quen se xubilaba tras máis de trinta anos de docencia universitaria ininterrompida. Baixo o título "Dez poetas da saudade" tivo lugar un recital poético de poesía galega e portuguesa. Esta actividade permitiu iniciar unha colaboración entre ambas as dúas linguas con vontade de continuidade no tempo, para organizar eventos semellantes.

Desde o CEG deuse difusión a través das nosas canles de información de numerosas propostas externas que nos foron chegando, tentando que sempre houbese representación e colaborando con elas na medida do posíbel. A capacidade informativa do centro medrou considerabelmente, o que se notou no incremento de seguidores a través da nosa páxina de facebook e no alcance das nosas publicacións na mesma. Foi a través deste medio, por exemplo, que establecemos unha colaboración coa iniciativa radiofónica burelés Proxecto Neo, a cargo do profesor Bernardo Penabade, con quen realizariamos varias entrevistas para o seu programa e mais manteriamos contacto na excursión galega anual. Logo, ademais de participar en diferentes eventos como

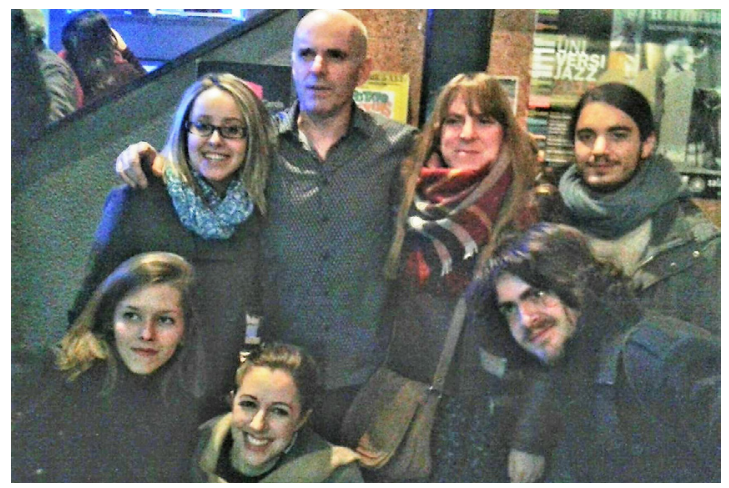

Concerto de Xabier Díaz e Adufeiras de Salitre, na Sala Galileo Galilei de Madrid presentacións de libros de escritores galegos en Madrid (Vicente Araguas, Marcelino Fernández Mallo), concertos de música (Xabier Díaz e Adufeiras de Salitre), recitais poéticos (Luz Pichel, Manuel Pereira, María do Cebreiro...) etc., aínda puidemos tomar parte de xeito especial coa celebración do Día de Rosalía e do Día da Poesía. Así mesmo, celebramos a tradicional excursión a Galicia e mais asistimos ás creacións de dous novos puntos de encontro para a colectividade galega en Madrid.

Novos espazos para a cultura galega emerxeron ao longo deste ano na capital, respondendo á demanda de puntos de encontro para a comunidade madrigalega e espazos onde compartir experiencias diversas. En primeiro lugar, xurdiu unha nova tertulia, ao abeiro da Escola Oficial de Idiomas Xesús Mateo. Con este encontro, suman xa tres as iniciativas semellantes na cidade: Enfiando Palabras e o Faladoiro. Unha vez ao mes, o exalumnado, o alumnado e as profesoras de lingua galega Neves González e Rosa María Dorrego, encóntranse na cafetería da EOI para falar sobre un tema, pactado de antemán. De asistencia libre, algunhas estudantes da universidade e a propia profesora lectora do CEG acoden esporadicamente, co obxectivo de coñecer outras persoas interesadas en practicar a lingua galega, apoiar as iniciativas que reforzan o tecido da comunidade galega en Madrid e tender pontes entre as dúas institucións. En segundo lugar, no mes de xuño foi presentado nos medios o colectivo Fenda (Embaixada Popular Galega), unha asociación político-cultural de carácter nacionalista (mais non partidista), baixo a cal se aglutinaron galegos e galegas residentes en Madrid con vontade de transformación social e de levar a cabo actividades galeguistas de diversa índole.

Chegadas as datas, recuncamos tanto no recital do Día de Rosalía, coma no Día da Poesía na UCM. Mentres que a celebración rosaliana da rúa Ballesta vén de confirmarse como unha das actividades estrela do galego en Madrid, o día adicadado ao xénero poético vai facéndose un oco polo seu propio peso na axenda complutense. O CEG asistiu ao primeiro co seu alumnado, para homenaxear á nosa poeta máis internacional lendo os seus textos, e convidou tamén ao poeta e investigador da UCM, Diego Román, quen tivo a ben recitar a "Negra sombra" en latín. Deste feito, fíxose eco a prensa galega, onde Xesús Alonso Montero redactou un artigo narrando os acontecementos. 


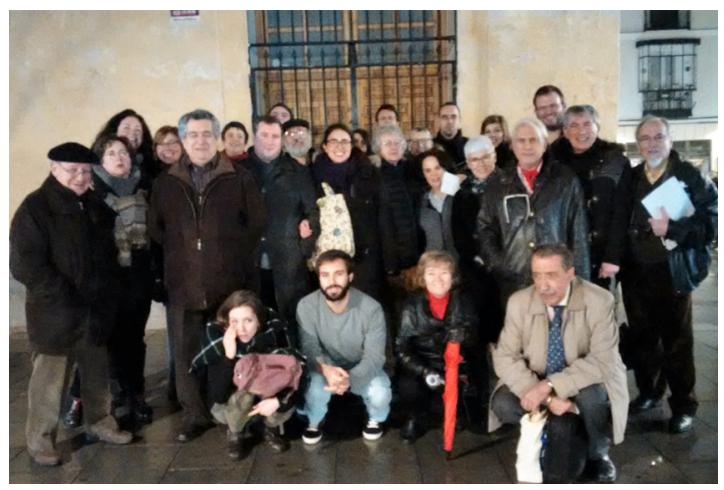

Asistentes ao Día de Rosalía, na Igrexa de San Ildefonso.

Conxuntamente con Diego Román outra vez e mais coa filóloga Noa Presas Bergantiños, o CEG tamén participou no deseño e impartición da actividade "Cartopoéticas", un obradoiro de poesía e xénero epistolar realizado o día 31 de marzo en dúas sesións, unha para adultos e outra para alumnado de secundaria. Nel foron lidos e dados a coñecer poemas en diversas linguas, destacando textos de Olga Novo e Manuel Antonio, ao mesmo tempo que lles servían aos rapaces e rapazas para recrear os seus propios.

Por motivos organizativos, este ano, a excursión a Galicia celebrouse non cara a finais do segundo semestre, como viña sendo tradicional, senón en Semana Santa. Este ano visitamos as provincias de Lugo, así como tamén, brevemente, A Coruña e Pontevedra. Ademais, como novidade, este ano contamos tamén na nosa viaxe coa compaña de estudantes de Turismo e mais unha estudante de mestrado. $\mathrm{O}$ itinerario partiu de Lugo, onde tivemos ocasión de coñecer diferentes xacementos romanos dentro do casco histórico e o seu Museo

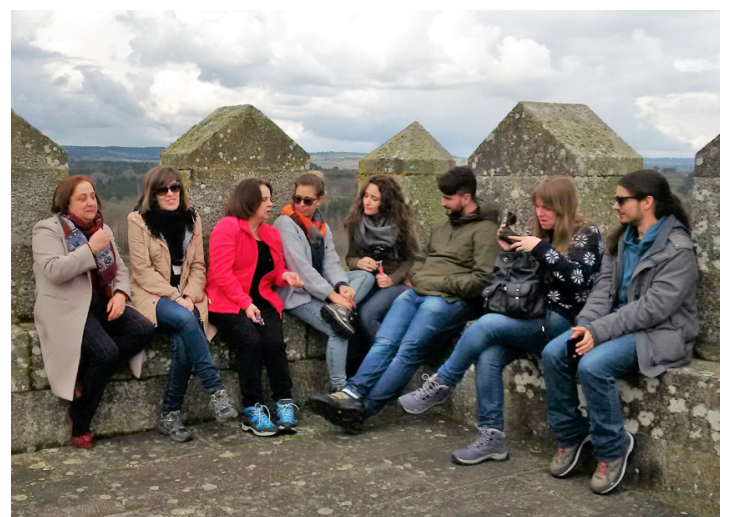

Fortaleza de San Paio de Narla (Friol, Lugo), entre as ameas
Provincial. Permanecemos na cidade dúas noites, movéndonos desde aquí a outras partes. Seguimos a nosa viaxe deténdonos no monumento Santa María de Bóveda, no Pazo de San Miguel da Retorta, que nos foi amablemente ensinado polos seus actuais donos e, finalmente, no Museo Fortaleza de San Paio de Narla, onde fomos recibidos polo persoal do museo e atendidos por Francisca Abuín. No camiño á Mariña Lucense, paramos para coñecer Mondoñedo. Bernardo Penabade, José Luis Fernández Ansedes, Xulio Rodríguez e mais Abel Vigo acompañáronnos a través dun fermoso percorrido urbano, visitando, entre outros espazos, a Casa dos Escritores, o casco histórico, o cemiterio civil e mais a tumba de Álvaro Cunqueiro. Alí recitamos e lembramos a algúns dos escritores mindonienses. A pesar do mal tempo, aínda puidemos facer un parte da ruta literaria do tamén escritor Leiras Pulpeiro, visitando unha pequena fervenza no medio da natureza. A segunda parte da viaxe tivo lugar na costa norte galega, onde pernoctamos outras dúas noites. Con base na vila mariñeira de Viveiro, visitamos, a maiores, Burela (da man, novamente, de Bernardo Penabade), Rinlo, a praia das Catedrais e Ribadeo (na compaña de Suso Acevedo). A ruta de sendeirismo desta edición tamén recortaba o perfil costeiro, desde Faro de Candieira, tamén coñecido como faro das dez curvas, a San Andrés de Teixeido, onde puidemos acceder ao Santuario e coñecer un pouco máis sobre este lugar de peregrinación. De alí saímos xa cara a Santiago, desde onde realizamos unha última xornada. Ao día seguinte, na compaña de Valentín García (Secretario Xeral de Política Lingüística), Armando Requeixo (escritor e investigador literario) e do profesor José Luis López Taboada, fixemos

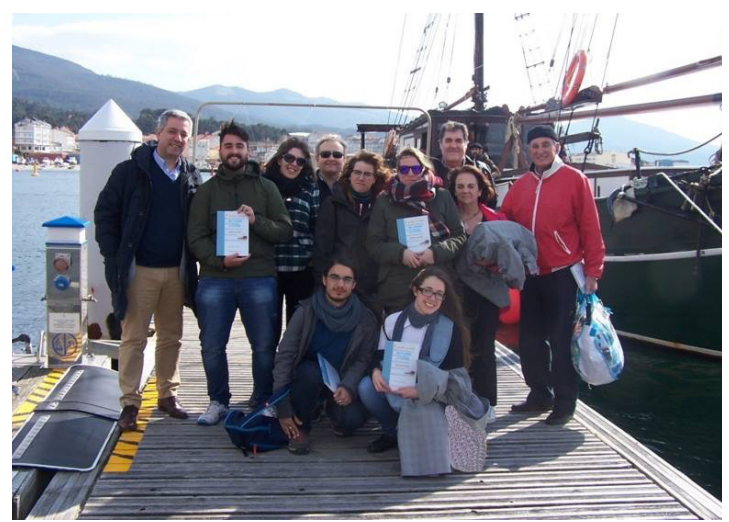

Antes de iniciar a singradura, Valentín García agasalla aos estudantes con De 4 a 4, de Manuel Antonio 
unha singradura pola ría de Muros e Noia, até a Ponte Nafonso, abordo do veleiro máis antigo de Galicia, o Joaquín Vieta. Durante a travesía, aprendemos moito sobre carpintería de ribeira e outras historias sobre a rexión, grazas ao noso guía, Juan López, e a restante tripulación. Puidemos tamén disfrutar dunha pequena conferencia sobre os poetas da comarca a cargo de Armando Requeixo e o alumnado recibiu, como agasallo, varios libros de poesía. Finalizamos o día en Vilagarcía de Arousa, até a onde nos achegamos para asistir a un concerto de música galega a cargo de Christian Silva, quen presentaba o seu novo traballo.

Pechamos o curso académico cun acto da revista Olga, na Casa de Galicia, o 28 de xuño de 2016. O partida de Sabino Torres foi o motivo de que os seus compañeiros (Vicente Araguas, Manuel Pereira e mais Rafa Yáñez) concibiran esta primeira presentación como unha homenaxe á súa persoa. Ademais das palabras que lle adicaron, contou coa voz dos poetas participantes neste primeiro volume, recitaron os textos da revista, e mais coa súa neta, Laura Mundo e sobriño, Francis Lorenzo. Foi unha fermosa maneira de despedilo, vendo a luz unha publicación que fará perdurar, por moitos anos, a súa memoria.

$$
* * *
$$

Ao remate desta publicación tivemos coñecemento do falecemento de Fermín Bouza Álvarez, aos setenta anos de idade, tras loitar contra unha dura enfermidade que non logrou superar. A nova conmoveu á cultura e sociedade galegas, nas que Fermín ocupou, desde ben cedo, un posto destacado. A súa marcha deixa unha cadeira baleira máis entre a galeguidade afincada en Madrid. Desde a redacción, queremos sumarnos ao pesar da súa familia e amizades cunha lembranza agarimosa.

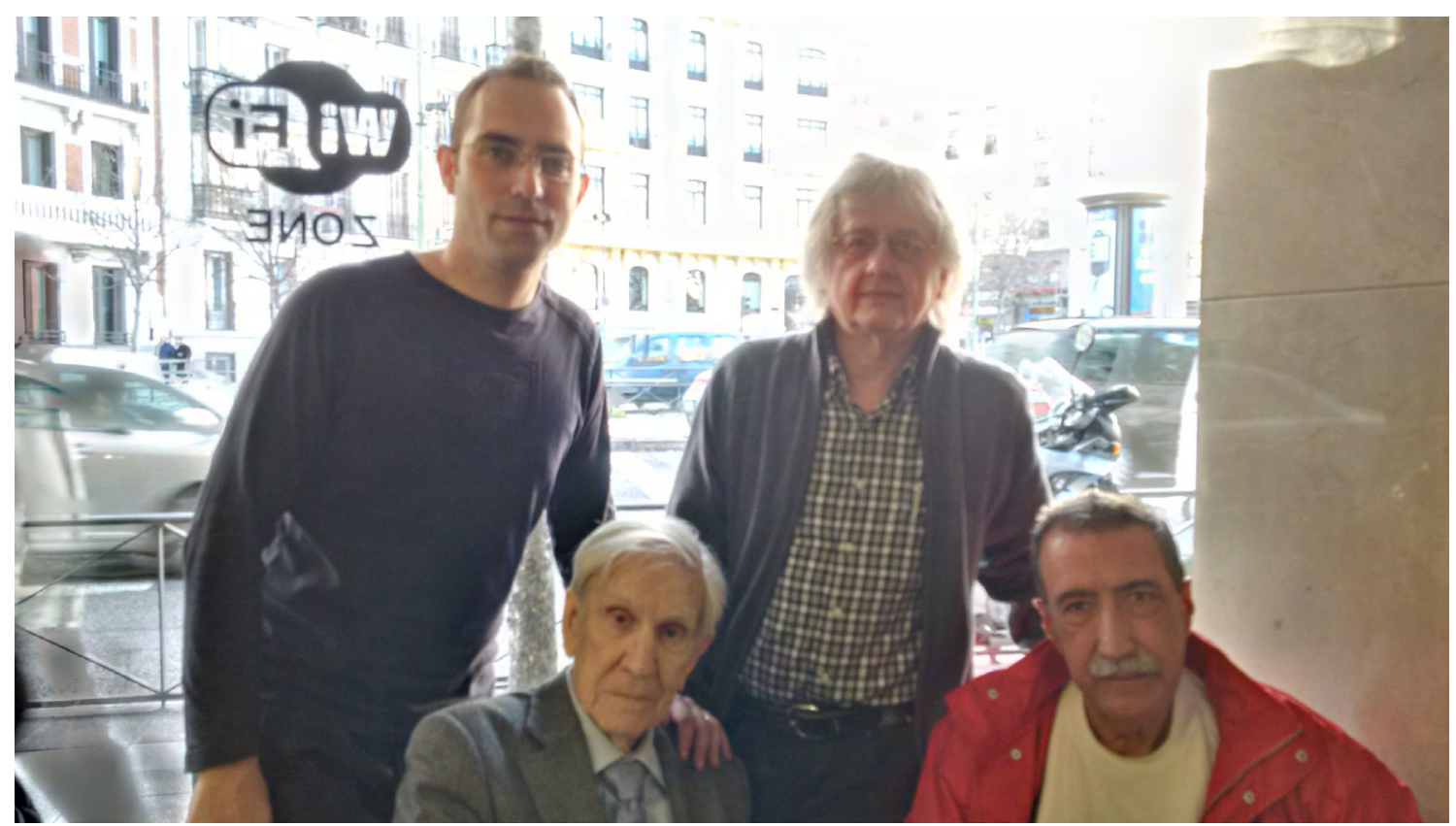

Dirección da revista Olga, de esquerda a dereita: Rafa Yáñez, Sabino Torres, Manuel Pereira e Vicente Araguas 